Check for updates

Cite this: RSC Adv., 2017, 7, 49074

Received 11th August 2017

Accepted 15th October 2017

DOI: $10.1039 / \mathrm{c} 7 \mathrm{ra} 08886 \mathrm{~h}$

rsc.li/rsc-advances

\section{High mechanical properties of epoxy networks with dangling chains and tunable microphase separation structure}

\author{
Yizhou Huang, (D) Yazhou Tian, Yuanyuan Li, (D) Xiaocun Tan, Qing Li, Jue Cheng* \\ and Junying Zhang*
}

A series of epoxy systems with tunable rigid-flexibility were prepared by the curing reaction of bisphenol $\mathrm{F}$ diglycidyl (DGEBF), a single-ended amine with alkyl chains ( $n$-butyl, octyl, dodecyl), 4,4'diaminodiphenylmethane (DDM) and 4,4'-diaminodicyclohexylmethane (H-DDM). By means of adjusting the composition of the curing agent (the molar ratio between $\mathrm{H}$-DDM and DDM), nano- and submicronsized phase separations were observed by atomic force microscopy (AFM). And diffraction peaks were not observed in the wide angle X-ray scattering (WAXS) characterization which revealed that there was no crystallization in the modified epoxy resin. Besides, the result of nanolR characterization proved that the aggregation of aliphatic chains led to the microphase separation structure, which can remarkably improve the mechanical properties of epoxy resins. The effects of side chains on the mechanical and thermal properties of epoxy networks were investigated. Especially, the $E_{C 8}-5^{\prime}$ (the molar ratio between $\mathrm{H}$-DDM and DDM was 45/55, the mass ratio of the $n$-octyl amine to DGEBF was $5: 100$ ) sample exhibited splendid mechanical properties with an attractive tensile strength of $88.4 \mathrm{MPa}$, an elongation at break of $6.6 \%$ and a tensile modulus of $3.5 \mathrm{GPa}$.

\section{Introduction}

Epoxy resins are used extensively as coatings, adhesives, and structural composite materials due to their excellent engineering properties. ${ }^{1}$ However, the inherently highly cross-linked molecular structures also give shortcomings, such as poor resistance to fracture and low fracture toughness. ${ }^{2}$ Consequently, an enormous amount of research effort goes into toughening epoxy polymers. Traditional toughening methods include the incorporation of soft materials such as rubber particles, ${ }^{3,4}$ core/shell particles, ${ }^{5,6}$ block copolymers (BCPs), ${ }^{7-9}$ et al. However, soft segments can significantly improve toughness with a sharp reduction of strength, modulus and glass transition temperature $\left(T_{\mathrm{g}}\right)$. It has also been demonstrated that toughness can be greatly improved by using rigid nanoparticles such as carbon nanotubes, ${ }^{10-12}$ silica, ${ }^{13-15}$ titania, ${ }^{16,17}$ alumina ${ }^{18,19}$ and POSS. ${ }^{20}$ Meanwhile, the presence of such fillers can increase modulus without sacrificing $T_{\mathrm{g}}$. However, it leads to agglomeration and reduces the processability of a material. Recently, studies have focused on novel approaches to toughen epoxy thermosets. For instance, interpenetrating networks ${ }^{21,22}$ and hyperbranched polymer ${ }^{23,24}$ can not only toughen epoxy resin

The Key Laboratory of Beijing City on Preparation and Processing of Novel Polymer Materials, Beijing University of Chemical Technology, Beijing 100029, China. Fax: +86 106442 5439; Tel: +86 106442 5439. E-mail: chengjue@mail.buct.edu.cn; zhangjy@mail.buct.edu.cn but also improve modulus without sacrificing $T_{\mathrm{g}}$ which has attracted the attention of researchers. However, prohibitive costs and complicated preparation limit the applications of these strategies.

Tao Yang et al. ${ }^{25}$ discovered that the side aliphatic chains would facilitate the self-assemble into bump structures, which were proved to toughen the epoxy resins. Longhan Ba et al. ${ }^{26}$ had discussed the mechanical properties and toughening mechanisms of the diglycidyl ether of bisphenol F (DGEBF) modified by partly reacting with monofunctional epoxy. Effect of different length and content of side chains on mechanical properties has been discussed. ${ }^{26}$ The major corresponding toughening mechanism of bump structure in the modified epoxies was attributed to the combination of shear yielding and bridging constraint effect. ${ }^{25,26}$ It was speculated that the appearance of microphase separation was the result of the incompatibility between the flexible side chains and rigid backbone of benzene ring. However, there are few studies on the effect of curing agent structure on the microphase separation behaviors.

Comprehensive understanding of the formation process of microphase separation structure is required by efficient design of ameliorated materials. Only in this way, their structures can be optimized and the inherent defects can either be eliminated or reduced. In this work, the influence of curing agent structure, the length and content of flexible side chain on morphology and mechanical properties were systematically studied. The appearance of microphase separation was achieved by adjusting 
the compatibility of the main chains and the side chains and the rigidity of crosslinking networks which was accomplished by tuning the molar ratio of 4,4'-diaminodiphenylmethane (DDM) and 4,4'-diaminodicyclohexylmethane (H-DDM) in the curing agent. Meanwhile, three kinds of the single-ended amine with alkyl chains ( $n$-butyl, octyl, dodecyl) were introduced in the cured epoxy networks and the effect of the length and content of the alkyl chains on the morphology was investigated. The variation tendency of microphase separation was examined by atomic force microscopy (AFM). The internal components of bump structures were studied by nanoIR, which allows nanoscale measurements of infrared absorption as a function of the wavenumber to characterize specimens at spatial resolutions not achievable previously. ${ }^{27,28}$ The formation mechanism of the microphase separation was expatiated. Moreover, tensile tests, impact tests and dynamic mechanical analysis (DMA) results were carried out for the investigation of the mechanical and thermal mechanical properties.

\section{Experimental section}

\subsection{Materials}

DGEBF (trade name Epon170, equivalent epoxy weight $165.3 \mathrm{~g}$ $\mathrm{mol}^{-1}$ ) was bought from Epoxy Division of China Petrochemical Group Baling Petrochemical Co., Ltd. Single-ended aliphatic amine ( $n$-butylamine, $n$-octylamine, $n$-dodecylamine), DDM $(98 \%+)$ and H-DDM $(98 \%+)$ were purchased from Aladdin Industrial Corporation. The molecular structures of these materials are shown in Fig. 1.

\subsection{Preparation of modified epoxy resin networks with side aliphatic chains induced by single-ended aliphatic amine}

DGEBF were mixed with DDM according to the stoichiometric ratio, and then single-ended aliphatic amine was loaded (mass ratio of the aliphatic amine between epoxy group of DGEBF was $2.5: 100$ and $5: 100)$. Subsequently, the blends were stirred homogeneously for $10 \mathrm{~min}$. After the pre-cured process under $60{ }^{\circ} \mathrm{C}$ for $2 \mathrm{~h}$, the reaction mixture was cured under $100{ }^{\circ} \mathrm{C}$ for another $2 \mathrm{~h}, 130^{\circ} \mathrm{C}$ for $2 \mathrm{~h}$ and $150{ }^{\circ} \mathrm{C}$ for $4 \mathrm{~h}$. The cured samples were named as $\mathrm{E}_{\mathrm{C} 4}, \mathrm{E}_{\mathrm{C} 8}$ and $\mathrm{E}_{\mathrm{C} 12}$ according to the carbon number
Table 1 Formulations of DGEBF/DDM/single-ended aliphatic amine systems (mass ratio of epoxy group)

\begin{tabular}{lllllll}
\hline Sample & $\mathrm{E}_{\mathrm{C} 4}-2.5$ & $\mathrm{E}_{\mathrm{C} 4}-5$ & $\mathrm{E}_{\mathrm{C} 8}-2.5$ & $\mathrm{E}_{\mathrm{C} 8}-5$ & $\mathrm{E}_{\mathrm{C} 12}-2.5$ & $\mathrm{E}_{\mathrm{C} 12-5}$ \\
\hline$n$-Butylamine & 2.5 & 5 & - & - & - & - \\
$n$-Octylamine & - & - & 2.5 & 5 & - & - \\
$n$-Dodecylamine & - & - & - & - & 2.5 & 5 \\
DGEBF & 100 & 100 & 100 & 100 & 100 & 100 \\
DDM & 26.2 & 22.8 & 27.7 & 25.8 & 28.3 & 26.9 \\
\end{tabular}

in the alkyl chains of the amine, and the pure $\mathrm{E}_{0}$ system (mass ratio of amine and DGEBF is $0 / 100$ ) was called the blank sample.

Then, DGEBF were well mixed with DDM and H-DDM according to the stoichiometric ratio and the $n$-octylamine was loaded (mass ratio of the $n$-octylamine between DGEBF was 5 : 100). For example, the $\mathrm{E}_{\mathrm{C} 8}-5$ cured by DDM and H-DDM (the molar ratio between H-DDM and DDM was 20/80) instead of pure DDM was named as $\mathrm{E}_{\mathrm{H}^{-}}-20$.

Last, DGEBF were mixed with DDM and H-DDM according to the stoichiometric ratio (the molar ratio between H-DDM and DDM was 45/55) and then single-ended aliphatic amine was added (mass ratio of the aliphatic amine between epoxy group of DGEBF was $2.5: 100$ and $5: 100)$. For example, $\mathrm{E}_{\mathrm{C} 4}-5$ cured by $\mathrm{H}-\mathrm{DDM} / \mathrm{DDM}$ instead of DDM was named as $\mathrm{E}_{\mathrm{C} 4}-5^{\prime}$. The detailed formulations of all the samples were listed in Tables 1, 2 and 3.

\subsection{Characterization techniques}

2.3.1 Atomic force microscopy (AFM). Morphology was characterized by tapping mode atomic force microscopy (AFM, Nanoscope IIIa, Bruker, Germany) under ambient conditions $\left(22^{\circ} \mathrm{C}\right)$ using a tip fabricated from silicon $(130 \mu \mathrm{m}$ in length with $0.99 \mathrm{MHz}$ resonant frequency).

2.3.2 Wide angle X-ray scattering (WAXS). Wide angle X-ray scattering was used to characterize the crystallization of these dispersed phase structures. A WAXS apparatus (Rigaku D/Max 2500VB2+/PC) was utilized for this purpose diffracted meter with $\mathrm{Cu} \mathrm{K} \alpha$ radiation.

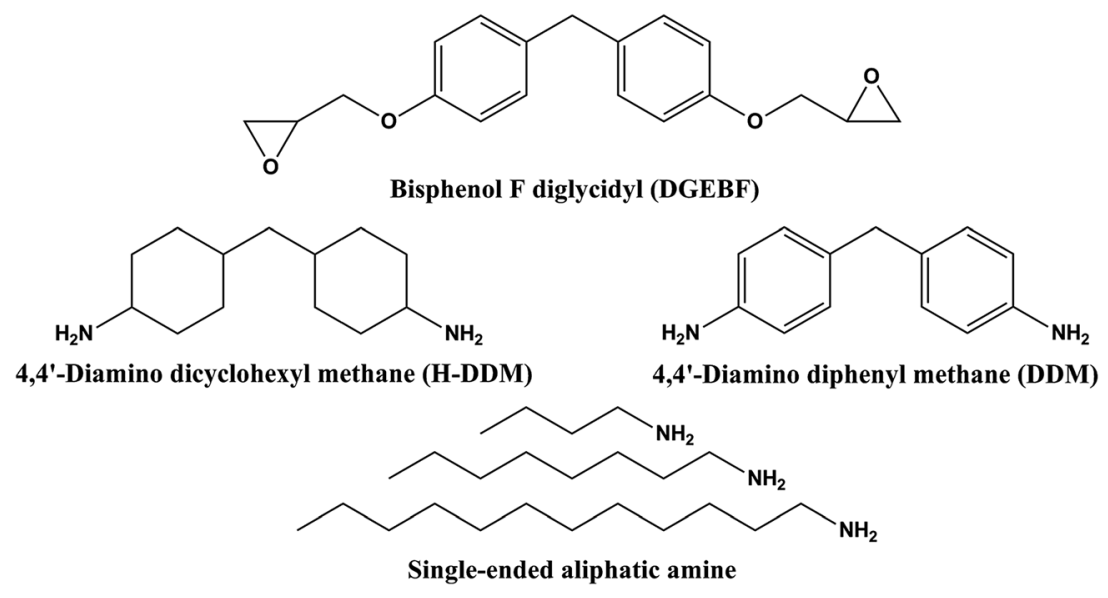

Fig. 1 Structures of the main chemicals used in this study. 
Table 2 Formulations of DGEBF/DDM/H-DDM/n-octylamine systems (mass ratio of epoxy group)

\begin{tabular}{|c|c|c|c|c|c|c|c|c|c|}
\hline$n$-Octylamine & 5 & 5 & 5 & 5 & 5 & 5 & 5 & 5 & 5 \\
\hline DGEBF & 100 & 100 & 100 & 100 & 100 & 100 & 100 & 100 & 100 \\
\hline H-DDM & 5.5 & 6.8 & 8.2 & 9.6 & 10.9 & 12.3 & 13.7 & 15.1 & 16.4 \\
\hline
\end{tabular}

Table 3 Formulations of DGEBF/DDM/H-DDM/single-ended aliphatic amine systems (mass ratio of epoxy group)

\begin{tabular}{|c|c|c|c|c|c|c|c|}
\hline Sample & $\mathrm{E}_{0}{ }^{\prime}$ & $\mathrm{E}_{\mathrm{C} 4^{-}}-2.5^{\prime}$ & $\mathrm{E}_{\mathrm{C} 4^{-} 5^{\prime}}$ & $\mathrm{E}_{\mathrm{C} 8}-2.5^{\prime}$ & $\mathrm{E}_{\mathrm{C} 8^{-}} 5^{\prime}$ & $\mathrm{E}_{\mathrm{C} 12}-2.5^{\prime}$ & $\mathrm{E}_{\mathrm{C} 12}-5^{\prime}$ \\
\hline$n$-Butylamine & - & 2.5 & 5 & - & - & - & - \\
\hline$n$-Octylamine & - & - & - & 2.5 & 5 & - & - \\
\hline DGEBF & 100 & 100 & 100 & 100 & 100 & 100 & 100 \\
\hline DDM & 16.3 & 14.4 & 12.6 & 15.2 & 14.2 & 15.6 & 14.8 \\
\hline H-DDM & 14.2 & 12.5 & 10.9 & 13.2 & 12.3 & 13.5 & 12.9 \\
\hline
\end{tabular}

2.3.3 NanoIR. A nanoIR2-FS (Anasys Instruments, USA) was used to characterize the sample of $\mathrm{E}_{\mathrm{C} 8}-5^{\prime}$ in contact mode. The spectra were collected with a sampling of $1 \mathrm{~cm}^{-1}$ and $128 \mathrm{co}-$ averages, within the standard wave number range of 900$1980 \mathrm{~cm}^{-1}$ and $2520-3600 \mathrm{~cm}^{-1}$.

2.3.4 Dynamic mechanical analysis (DMA). A DMA Q-800 (TA Instruments, USA) was used to study the dynamic mechanical properties of the cured epoxy resin. Analysis was performed using a film tension, at a dynamic frequency of $1 \mathrm{~Hz}$, in the temperature range $20-180{ }^{\circ} \mathrm{C}$ with a ramp of $3 \mathrm{~K} \mathrm{~min}^{-1}$. The dynamic storage modulus $\left(E^{\prime}\right)$ and $\tan \delta$ curves were plotted as a function of temperature. Specimen dimensions were $20 \mathrm{~mm}$ $\times 6 \mathrm{~mm} \times 0.6 \mathrm{~mm}$.

2.3.5 Differential scanning calorimetry (DSC). The glass transition temperatures $\left(T_{\mathrm{gDSC}}\right)$ of the $\mathrm{E}_{0}{ }^{\prime}, \mathrm{E}_{\mathrm{C} 4}-5^{\prime}, \mathrm{E}_{\mathrm{C} 8}-5^{\prime}$ and $\mathrm{E}_{\mathrm{C} 12^{-} 5^{\prime}}$ were tested using a TA Instruments Q20 DSC equipped with an RCS 90 cooling system. The 5-10 $\mathrm{mg}$ samples were sealed in aluminum crucibles with the following thermal program (dry nitrogen was used as the protective atmosphere, $50 \mathrm{~mL} \mathrm{~min}{ }^{-1}$ ): heating from $20{ }^{\circ} \mathrm{C}$ to $190{ }^{\circ} \mathrm{C}$ at $20{ }^{\circ} \mathrm{C} \mathrm{min}^{-1}$, cooling to $20{ }^{\circ} \mathrm{C}$ at the maximum cooling rate, and then reheating to $190{ }^{\circ} \mathrm{C}$ at $10{ }^{\circ} \mathrm{C} \mathrm{min}^{-1}$. The values of $T_{\mathrm{gDSC}}$ were measured from the second heating trace.

2.3.6 Mechanical tests. Tensile experiments were carried out by a testing machine (SANS UTM5205XHD, China) at room temperature according to Chinese National Standard GB/T 1040.2-2006. Young's modulus, tensile strength, and elongation at break were obtained on the basis of at least six specimens per sample. And the average was reported as the final value. And charpy impact test was measured by a XJJD impact tester (MTS systems Co., Ltd, China) according to Chinese National Standard GB/T 1843-2008, respectively.

\section{Results and discussion}

\subsection{Morphological behavior}

Fig. 2 shows the phase images of $\mathrm{E}_{\mathrm{C} 4}, \mathrm{E}_{\mathrm{C} 8}$ and $\mathrm{E}_{\mathrm{C} 12}$. This results suggested that microphase separation was absent in DGEBF/
DDM/single-ended aliphatic amine system. This phenomenon was different from the reports in the literature. ${ }^{25,26}$ Previous studies showed that bringing aliphatic pendant chains into epoxy matrix which was DGEBF cured by hexahydrophthalic anhydride (HHPA) would lead to microphase separation. Due to the structural and compatibility differences between aliphatic chain and backbone of epoxy resin which contains benzene ring, the flexible side chain self-assembly formed microphase separation in cured epoxy resin. ${ }^{25}$

However, there was no microphase separation observed by AFM when DDM instead of HHPA as the curing agent. It was speculated that the absence of microphase separation was due to the excess of regular benzene ring structures, which made the main chain particularly rigid. Furthermore, rigid main chain structure limited the movement of side chain prevented the selfassemble. It was speculated that the presence of microphase separation was not only related to the compatibility between the side chain and the main chain, but also limited by the rigidity of the backbone.

The composition of the curing agent was changed by tuning the molar ratio of $\mathrm{H}-\mathrm{DDM} / \mathrm{DDM}$ to adjust the rigid of the backbone (Table 2). Fig. 3 shows the phase images of DGEBF/ $\mathrm{DDM} / \mathrm{H}$-DDM/n-octylamine systems. For the $\mathrm{E}_{\mathrm{H}}-20$ system, uniformly distributed tiny phases were observed. For the $\mathrm{E}_{\mathrm{H}^{-}}-25$ system, similar and more pronounced phases were presented. When the ratio was $30 / 70$, clearly dispersed phases were observed, and more regular microphases appeared with the increasing of H-DDM content. When ratio exceeded 55/45, there was little phase separation. With the continuous reduction of the benzene ring, the compatibility between flexible side chain and backbone was getting better and better. However, good compatibility can't form phase separation. The results of phase images in Fig. 3 indicated that the rigidity of backbone played an important role in the formation of microphase separation. On the one hand, the rigidity of the main chain was deemed to the major factor affecting microphase separation when the content of H-DDM was relatively low. High rigidity of the main chain limited the chemical rotation of bonds making the side 

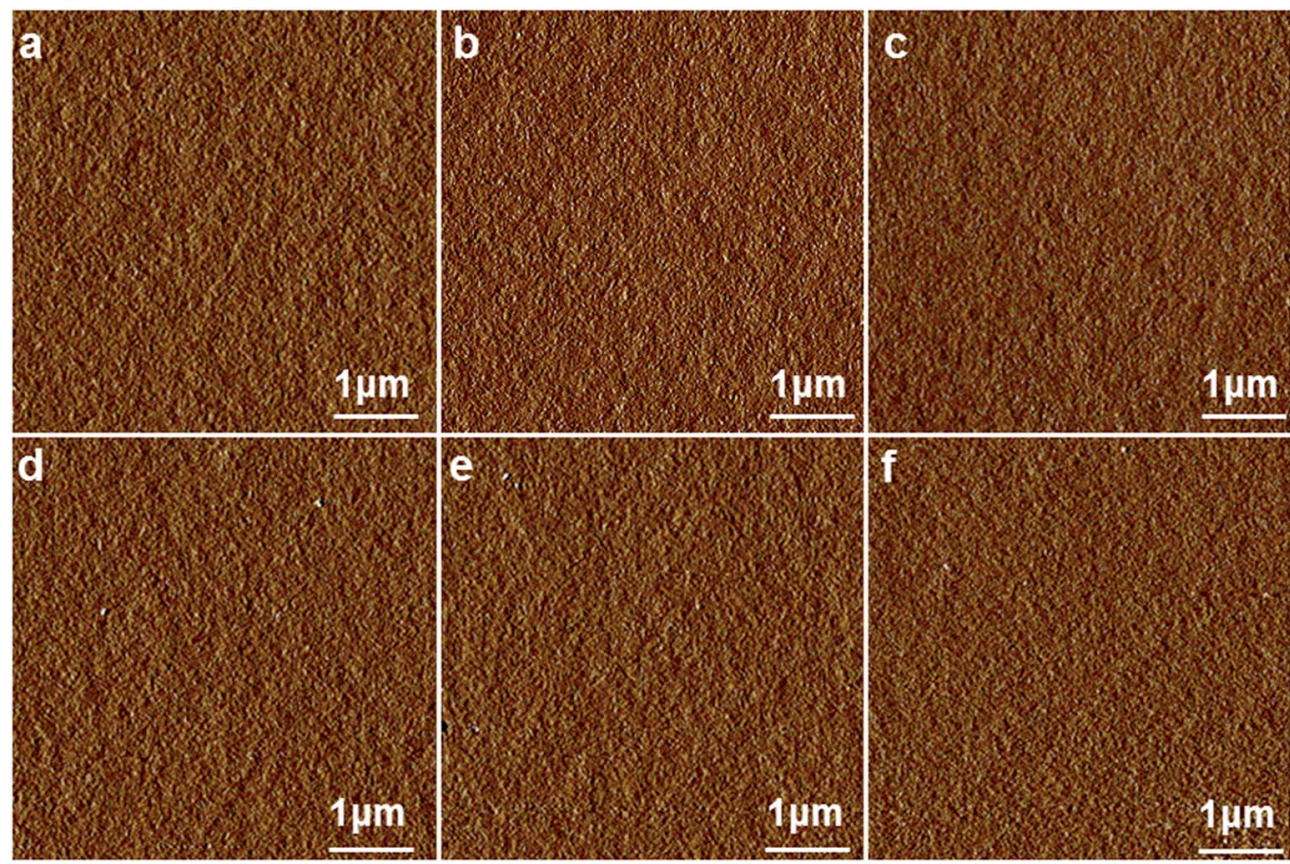

Fig. 2 AFM phase images of $E_{C 4}-2.5$ (a), $E_{C 8}-2.5$ (b), $E_{C 12}-2.5$ (c), $E_{C 4}-5$ (d), $E_{C 8}-5$ (e) and $E_{C 12}-5$ (f). The morphology of them was homogeneous and featureless.

chains difficult to self-assemble. On the other hand, when the H-DDM content was relatively high, the rigidity of the backbone limited the aggregation of side chains. At this moment, the compatibility between flexible side chain and backbone became the principal factor.

The uniformly distributed spherical bump structures were observed in (Fig. $3 \mathrm{~d}-\mathrm{f}$ ) $\mathrm{E}_{\mathrm{H}^{-}}-35, \mathrm{E}_{\mathrm{H}^{-}}-40$ and $\mathrm{E}_{\mathrm{H}^{-}}-45$ system, and the better distribution of submicro- and nano-structures were observed in the $\mathrm{E}_{\mathrm{H}}-45$ system. It was noted that the co-existence of submicro- and nano-sized bump structures had significant effect on the toughness of epoxy resins and improved the mechanical properties dramatically. ${ }^{25}$ Therefore, the following studies are carried out under this proportion (molar ratio of $\mathrm{H}^{-}$ DDM and DDM was 45/55) of the curing agent.

The DGEBF/DDM/H-DDM/single-ended aliphatic amine systems (Table 3) showed completely different morphologies from DGEBF/DDM/single-ended aliphatic amine systems (Table 1) in Fig. 4. After adjusting the composition of curing agent, all modified samples clearly showed different shapes and sizes of dispersed phases. When epoxy contained $2.5 \mathrm{phr}$ of side chains, sparse phase separation structures are shown in $\mathrm{E}_{\mathrm{C} 4}-2.5, \mathrm{E}_{\mathrm{C} 8}-2.5, \mathrm{E}_{\mathrm{C} 12-2.5}$ (Fig. 4a-c). When epoxy contained $5 \mathrm{phr}$ of side chains, the intensity of the dispersed bump structure increased (Fig. 4d-f). Moreover, regular spherical structures were observed in $\mathrm{E}_{\mathrm{C} 8}-5, \mathrm{E}_{\mathrm{C} 12^{-5}}$ (Fig. 4e and f). It was postulated that the difference in length of side aliphatic chains led to the size variation of the bump structure as well. For the $\mathrm{E}_{\mathrm{C} 8}$ system, massive nano-sized (30-50 nm) and submicron-sized (135-270 nm) found in $\mathrm{E}_{\mathrm{C}^{-5}}$ (Fig. 4e). Besides, nano-sized $(70-88 \mathrm{~nm})$ and submicron-sized (360$420 \mathrm{~nm}$ ) dispersed phases coexisted in $\mathrm{E}_{\mathrm{C} 12}-5$ (Fig. 4f). The phenomenon suggested that the longer length of side chains, the larger scale phase separations.

It was noteworthy that uniformly distributed spherical submicro- and nano-structures were observed in $\mathrm{E}_{\mathrm{C}^{-}} 5^{\prime}$ and $\mathrm{E}_{\mathrm{C} 12^{2}}-5^{\prime}$ systems. According to previous studies, ${ }^{25}$ similarly bump structure formed by self-assembly of side chains can dramatically improve mechanical properties. Consequently, the research emphases were put on the $5 \mathrm{phr}$ of side chain systems which were expected to have splendid mechanical properties.

\subsection{WAXS characterization}

WAXS curves of $\mathrm{E}_{0}, \mathrm{E}_{\mathrm{C} 4}-5^{\prime}, \mathrm{E}_{\mathrm{C} 8}-5^{\prime}$ and $\mathrm{E}_{\mathrm{C} 12}-5^{\prime}$ were showed in Fig. 5. The curve of $\mathrm{E}_{0}$ represented amorphous polymer. ${ }^{29}$ Besides, diffraction peaks were not found in $\mathrm{E}_{\mathrm{C} 4}-5^{\prime}, \mathrm{E}_{\mathrm{C} 8}-5^{\prime}$ and $\mathrm{E}_{\mathrm{C} 122^{-}}{ }^{\prime}$, which showed relatively more microphase separation. This results suggested that these bump structures were not composed of crystalline structures which was similar to that of polyethylene. $^{30}$

\subsection{NanoIR characterization}

The characterization technique, nanoIR, was carried out in order to investigate the real structure of microphase separation. The nanoIR is a probe-based measurement tool that reveals the chemical composition of samples at the nanoscale. ${ }^{31}$ Fig. 6 showed an AFM topographic image with lighter areas representing higher elevations of $\mathrm{E}_{\mathrm{C} 8} 5^{\prime}$ sample surface. The correspondingly colored plus signed in the middle panels identify the locations where the spectra at the bottom were collected. Representative spectra of A (red) and B (blue) were shown at the bottom of Fig. 6 . The stretch peak at $1608 \mathrm{~cm}^{-1}$ represented the benzene rings, and stretch around at 2930 and $2860 \mathrm{~cm}^{-1}$ stand 

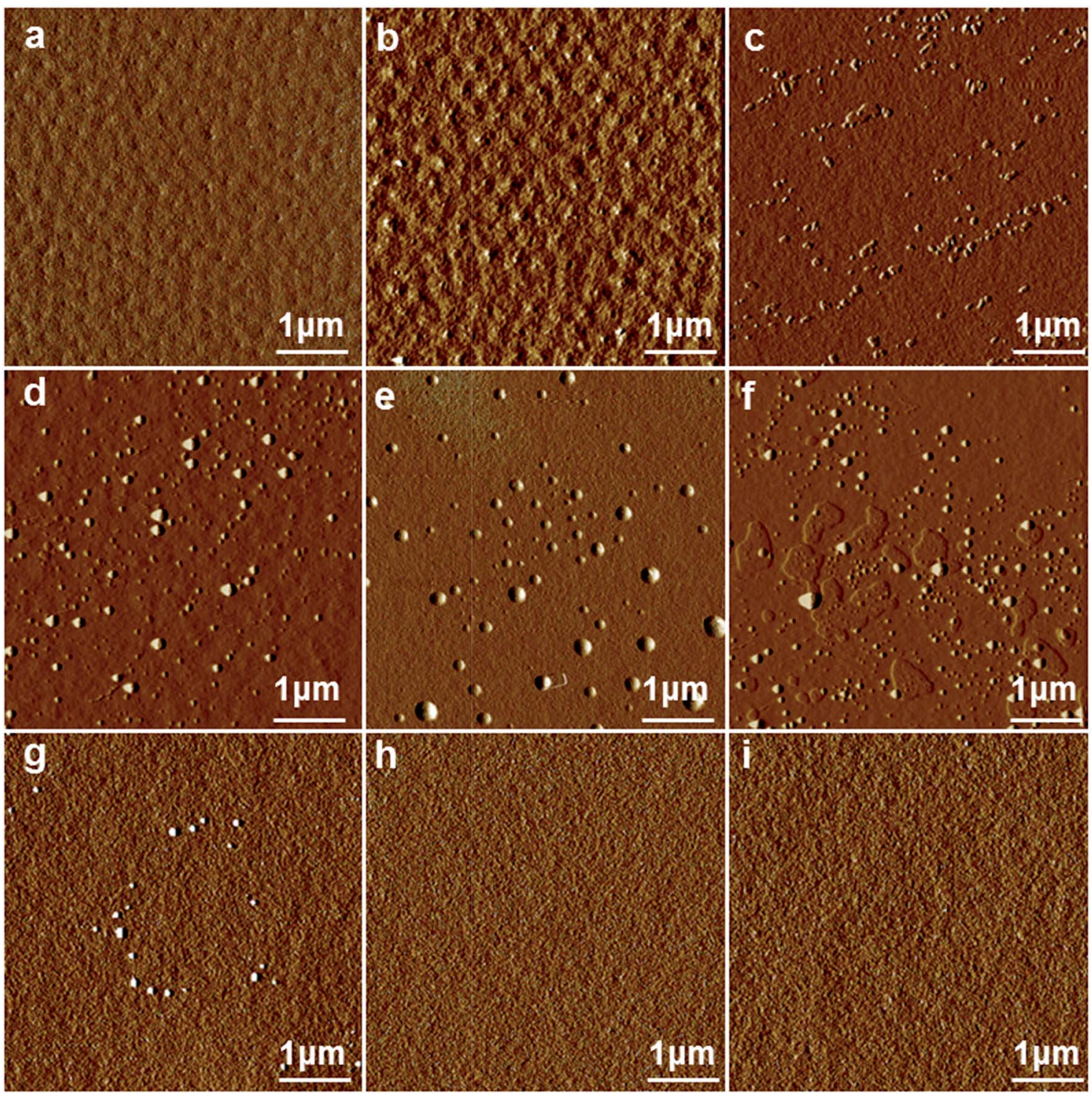

Fig. 3 AFM phase images of $E_{H^{-}}-20$ (a), $E_{H^{-}}-25$ (b), $E_{H^{-}}-30$ (c), $E_{H^{-}}-35$ (d), $E_{H^{-}}-40$ (e), $E_{H^{-}}-45$ (f), $E_{H^{-}}-50$ (g), $E_{H^{-}}-55$ (h), $E_{H^{-}}-60$ (i).

for the methylene $\mathrm{C}-\mathrm{H}$. It was observed that the intensity of the benzene ring stretch peak remains constant for two positions. It could be seen that the intensities at A were higher than B. It demonstrated that the methylene content of bump structure was higher than homogeneous structure. It indicated that the aggregation of aliphatic chain led to the microphase separation structure in this system.

\subsection{Mechanical properties}

Tensile tests and impact tests of $\mathrm{E}_{\mathrm{H}}$ and $E^{\prime}$ systems were performed in order to verify the effect of the microphase separation on mechanical properties. The results were given in Tables 4 and 5. For the $\mathrm{E}_{\mathrm{H}}$ system, the strength and modulus increased with the raise of the content of $\mathrm{H}$-DDM in a certain range (molar ratio of $\mathrm{H}$-DDM/DDM from 20/80 to 45-55). When the ratio got to $45 / 55$, the tensile strength and tensile modulus got to the maximum values (88.4 MPa and 3.5 GPa), which were consistent with our previous expectation that submicro- and nanostructures would improve mechanical properties dramatically. When the molar ratio of H-DDM exceeded 45/55, strength and modulus decreased. On the one hand, the increase of H-DDM content resulted in the decrease of rigidity of the whole network, which weakened the strength. On the other hand, adjusting the content of H-DDM affected the formation of microphase separation structure (Fig. 3). Therefore, little change in strength was owing to the interaction of these two results. However, tensile modulus varied apparently with the adjusting curing agent. As shown in AFM phase images (Fig. 3), the variation trend of the modulus coincided with the variation trend of morphologies. It was demonstrated that uniformly distributed spherical microphase separation had a profound effect on the improvement of tensile modulus. Based on the morphology characterizations by AFM, the verification of microphase separation structure by nanoIR and mechanical 

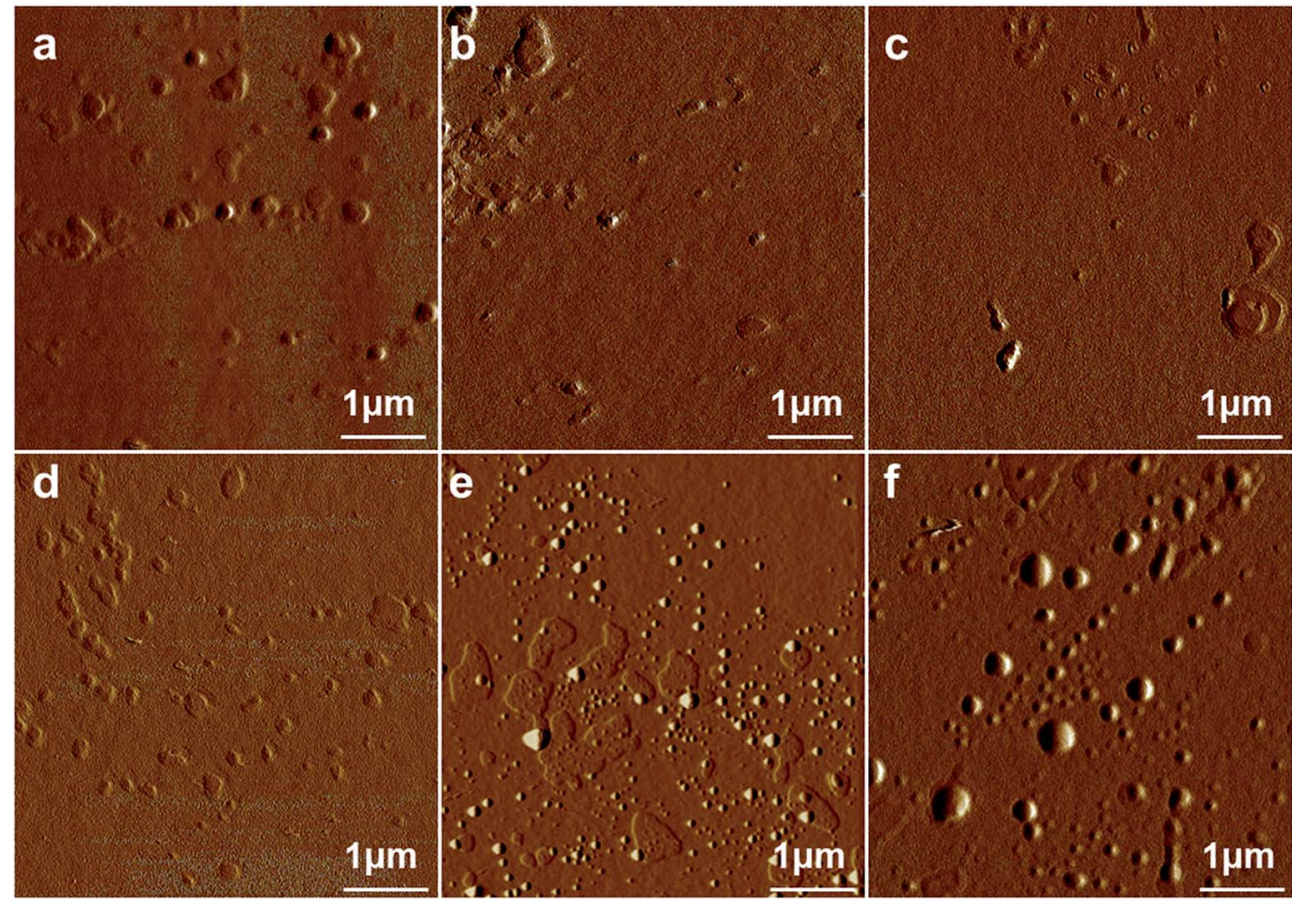

Fig. 4 AFM phase images of $E_{C 4}-2.5^{\prime}$ (a), $E_{C 8}-2.5^{\prime}$ (b), $E_{C 12}-2.5^{\prime}$ (c), $E_{C 4}-5^{\prime}$ (d), $E_{C 8^{-}}-5^{\prime}$ (e) and $E_{C 12}-5^{\prime}$ (f).

Table 4 Mechanical properties of $E_{H^{-}}-20, E_{H^{-}}-25, E_{H^{-}}-30, E_{H^{-}}-35, E_{H^{-}}-40, E_{H^{-}}-45, E_{H^{-}}-50, E_{H^{-}}-55$ and $E_{H^{-}}-60$

\begin{tabular}{|c|c|c|c|c|c|c|c|c|c|}
\hline Cured samples & $\mathrm{E}_{\mathrm{H}^{-20}}$ & $\mathrm{E}_{\mathrm{H}^{-25}}$ & $\mathrm{E}_{\mathrm{H}^{-}}-30$ & $\mathrm{E}_{\mathrm{H}^{-}}-35$ & $\mathrm{E}_{\mathrm{H}^{-}}-40$ & $\mathrm{E}_{\mathrm{H}^{-45}}$ & $\mathrm{E}_{\mathrm{H}^{-}} 50$ & $\mathrm{E}_{\mathrm{H}^{-}}-55$ & $\mathrm{E}_{\mathrm{H}^{-}}-60$ \\
\hline Tensile strength (MPa) & $84.1 \pm 1.7$ & $85.8 \pm 1.4$ & $85.3 \pm 0.8$ & $85.5 \pm 1.1$ & $88.2 \pm 0.9$ & $88.4 \pm 0.6$ & $85.1 \pm 1.1$ & $84.5 \pm 1.4$ & $82.4 \pm 1.3$ \\
\hline Elongation (\%) & $5.6 \pm 0.6$ & $6.1 \pm 0.4$ & $5.6 \pm 0.6$ & $6.7 \pm 0.5$ & $6.1 \pm 0.6$ & $6.6 \pm 0.8$ & $6.7 \pm 0.6$ & $6.2 \pm 0.7$ & $5.5 \pm 0.9$ \\
\hline Impact strength $\left(\mathrm{kJ} \mathrm{m}^{-2}\right)$ & $21.2 \pm 0.2$ & $22.2 \pm 1.3$ & $21.3 \pm 0.3$ & $20.5 \pm 0.7$ & $20.7 \pm 0.5$ & $21.1 \pm 0.4$ & $23.0 \pm 0.4$ & $21.2 \pm 0.5$ & $19.9 \pm 0.7$ \\
\hline
\end{tabular}

properties, it was tentatively interpreted the increasing of modulus to the decrease of free volume. Under the influence of aggregations of aliphatic chains, the main chains got closer. Namely, the

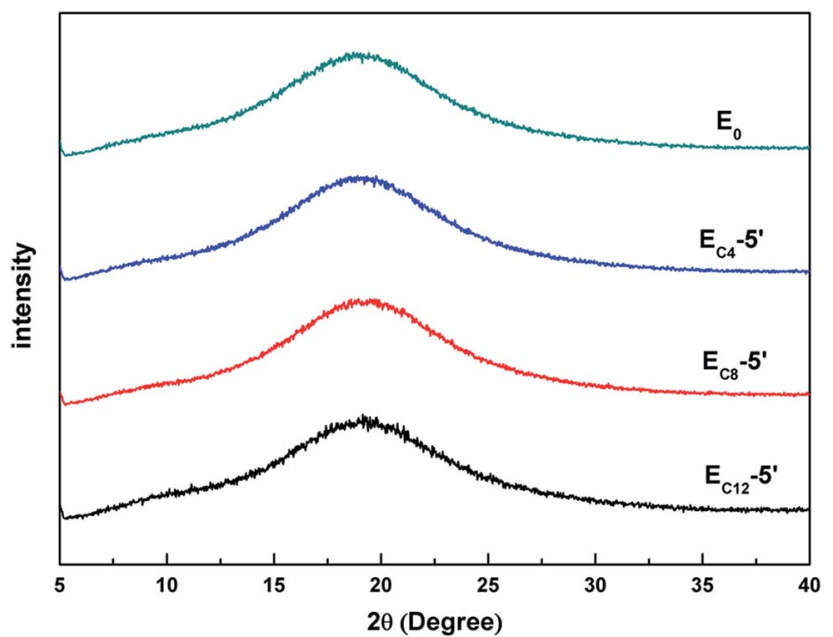

Fig. $5 X$-ray diffraction diagrams of cured $E_{0}, E_{C 4}-5^{\prime}, E_{C 8}-5^{\prime}$ and $\mathrm{E}_{\mathrm{C} 12}-5^{\prime}$. crosslinking networks piled up more tightly, which decreased the free volume. According to the reports in the literature, the decrease of free volume led to the increasing of modulus. ${ }^{32}$

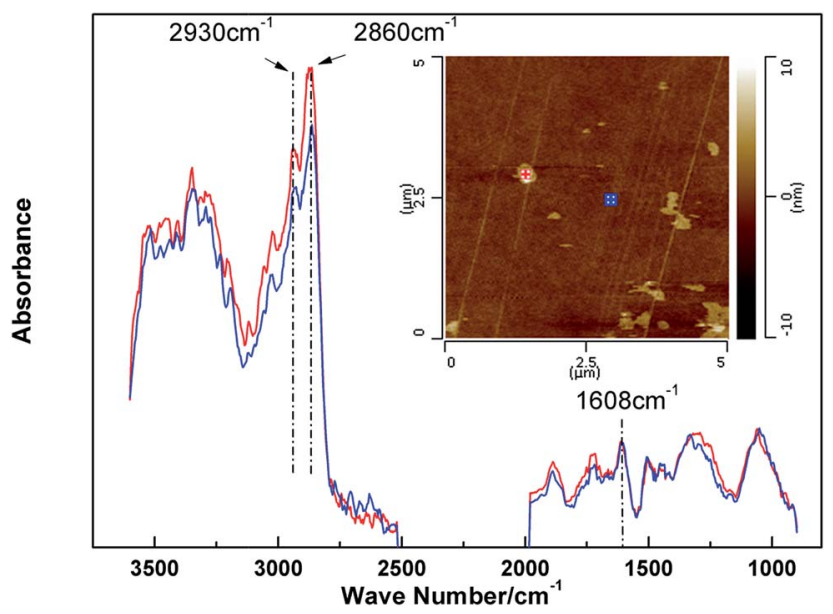

Fig. 6 Local microdomains of $E_{C 8}-5^{\prime}$. Contact mode AFM height image (top A-red, B-blue) and IR spectra at selected positions (bottom). 


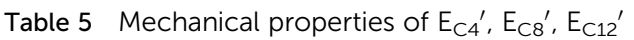

\begin{tabular}{|c|c|c|c|c|c|c|c|}
\hline Cured sample & $\mathrm{E}_{0}^{\prime}$ & $\mathrm{E}_{\mathrm{C} 4}-2.5^{\prime}$ & $\mathrm{E}_{\mathrm{C} 4}-5^{\prime}$ & $\mathrm{E}_{\mathrm{C} 8}-2.5^{\prime}$ & $\mathrm{E}_{\mathrm{C} 8^{-}} 5^{\prime}$ & $\mathrm{E}_{\mathrm{C} 12-2.5^{\prime}}$ & $\mathrm{E}_{\mathrm{C} 12^{-} 5^{\prime}}$ \\
\hline Tensile strength (MPa) & $76.1 \pm 1.4$ & $86.4 \pm 1.6$ & $85.84 \pm 1.8$ & $84.8 \pm 1.9$ & $88.4 \pm 0.6$ & $85.9 \pm 0.6$ & $86.1 \pm 1.3$ \\
\hline Elongation (\%) & $4.6 \pm 0.9$ & $6.1 \pm 0.9$ & $6.0 \pm 0.9$ & $6.2 \pm 0.8$ & $6.6 \pm 0.8$ & $6.1 \pm 0.8$ & $6.7 \pm 0.9$ \\
\hline Impact strength $\left(\mathrm{kJ} \mathrm{m}^{-2}\right)$ & $18.3 \pm 0.4$ & $24.1 \pm 1.1$ & $23.1 \pm 0.7$ & $20.5 \pm 0.6$ & $21.1 \pm 0.4$ & $19.8 \pm 0.7$ & $19.9 \pm 0.5$ \\
\hline
\end{tabular}
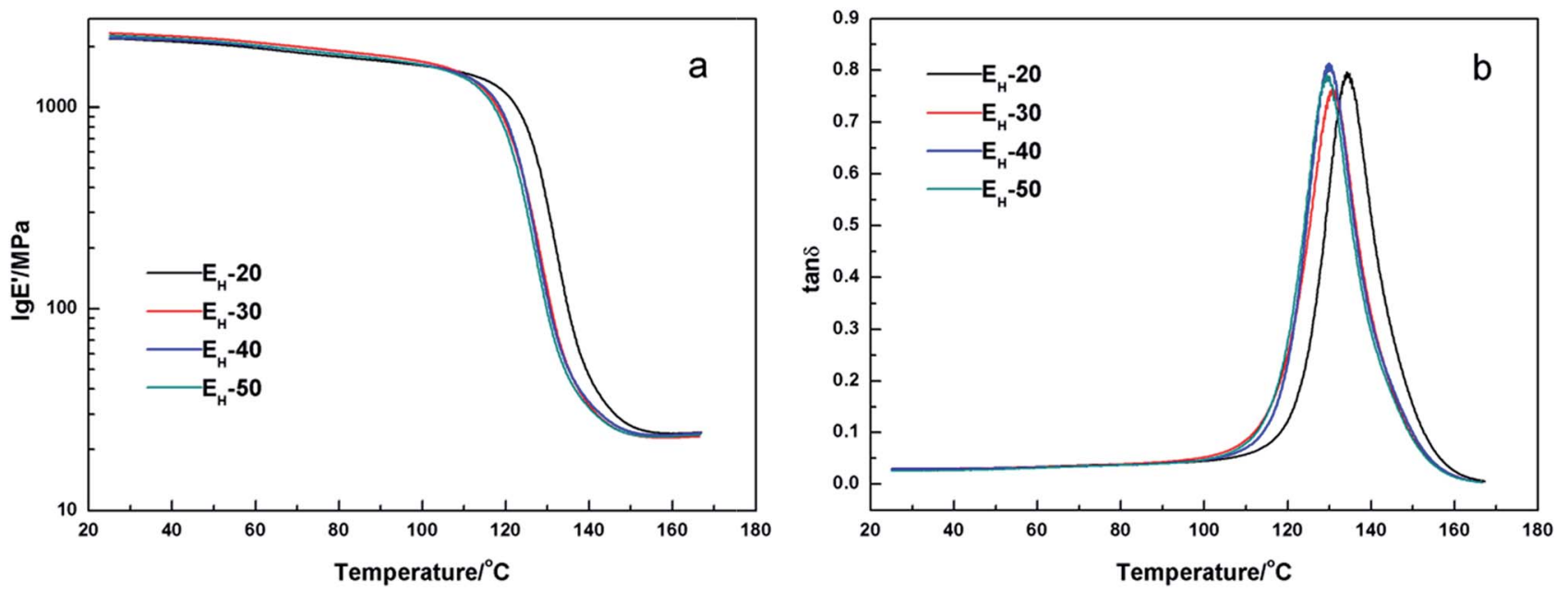

Fig. 7 Plots of storage modulus (a) and loss tangent (b) versus temperature of cured $E_{H^{-}}-20, E_{H^{-}}-30, E_{H}-40$, and $E_{H^{-}}-50$ systems.

The results of tensile test and impact test of cured $\mathrm{E}_{\mathrm{C} 4}{ }^{\prime}$, $\mathrm{E}_{\mathrm{C} 8}{ }^{\prime}, \mathrm{E}_{\mathrm{C} 12}{ }^{\prime}$ were listed in Table 5. A significant increase of mechanical properties was observed after introducing the microphase separation structure. It was proved that all the nano-, submicro-sized bump structures had a significant effect on the toughness of epoxy resins and enhanced the modulus dramatically. Adjusting the content and length of the aliphatic side chains was able to maximize the tensile strength, the tensile elongation at break and the tensile modulus (88.4 MPa, $6.6 \%$ and $3.5 \mathrm{GPa}$ for the $\mathrm{E}_{\mathrm{C} 8}-5^{\prime}$ sample). For the different length of side chain, strength did not change significantly. For $\mathrm{E}_{\mathrm{C} 8}^{\prime}$ and $\mathrm{E}_{\mathrm{C} 12}{ }^{\prime}$ system, strength and elongation at break increased with the raising of the content of side chain.

\subsection{DMA and DSC}

The thermal mechanical properties of the epoxy resins were investigated by DMA and the results were shown in Fig. 7-9. Little differences of the storage modulus were observed between these $E_{H}$ systems in glassy region or rubbery region because of the similar main structures in the crosslinking networks. The cross-linking density $\left(\nu_{\mathrm{e}}\right)$ can be able to be calculated from storage modulus in rubbery region according to the kinetic theory of rubber elasticity using the following equation ${ }^{33}$

$$
E^{\prime}=3 v_{\mathrm{e}} R T
$$

where $T_{\mathrm{g}}$ is the glass transition temperature, $E^{\prime}$ is the storage modulus at $T_{\mathrm{g}}+30{ }^{\circ} \mathrm{C}, R$ is the gas constant, and $T$ is the
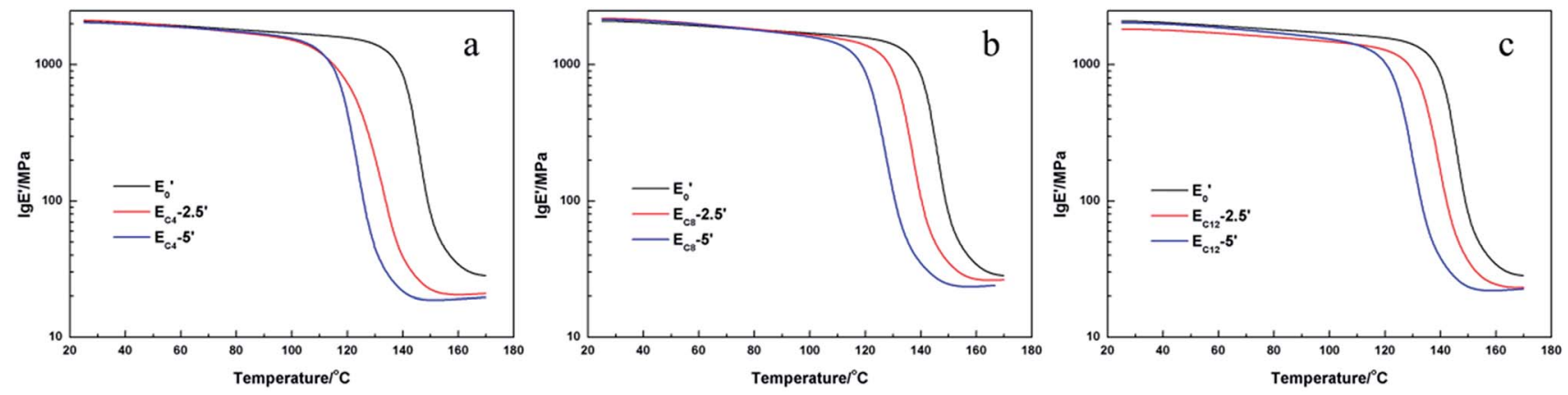

Fig. 8 Plots of storage modulus versus temperature of $\mathrm{E}_{\mathrm{C} 4}{ }^{\prime}(\mathrm{a}), \mathrm{E}_{\mathrm{C} 8}{ }^{\prime}$ (b) and $\mathrm{E}_{\mathrm{C} 12}{ }^{\prime}$ (c) systems. 

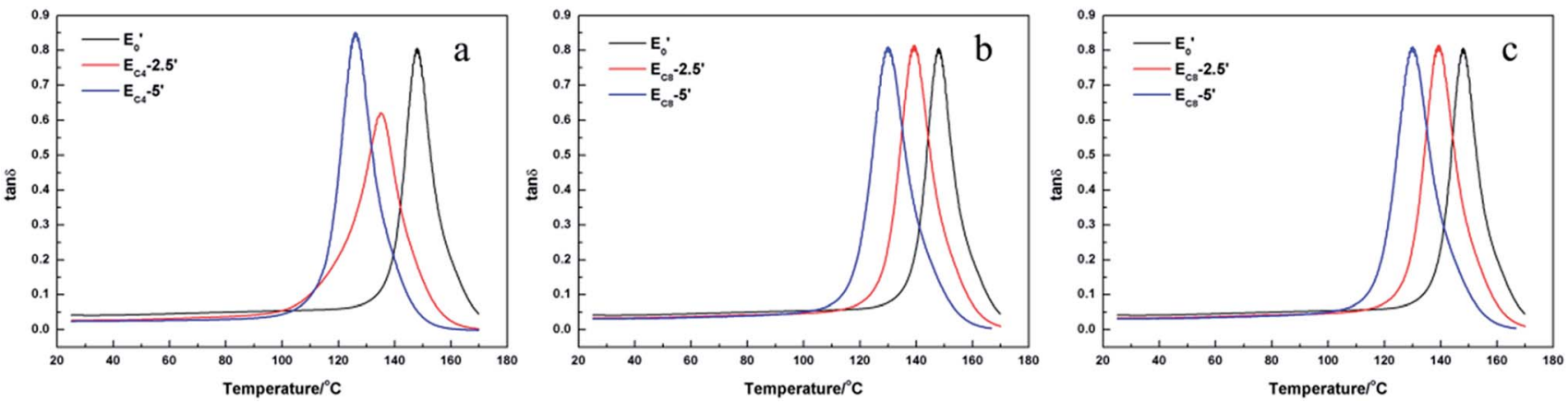

Fig. 9 Plots of loss tangent versus temperature of $\mathrm{E}_{\mathrm{C} 4}{ }^{\prime}(\mathrm{a}), \mathrm{E}_{\mathrm{C} 8}{ }^{\prime}(\mathrm{b})$ and $\mathrm{E}_{\mathrm{C} 12}{ }^{\prime}$ (c) systems.

Table 6 The values of $T_{\mathrm{g}}$ and crosslinking density $\nu_{\mathrm{e}}$ of $E_{\mathrm{H}}$ and $E^{\prime}$ systems

\begin{tabular}{|c|c|c|c|c|c|c|c|c|c|c|c|}
\hline Cured sample & $\mathrm{E}_{0}^{\prime}$ & $\mathrm{E}_{\mathrm{H}^{-20}}$ & $\mathrm{E}_{\mathrm{H}^{-30}}$ & $\mathrm{E}_{\mathrm{H}^{-40}}$ & $\mathrm{E}_{\mathrm{H}^{-50}}$ & $\mathrm{E}_{\mathrm{C} 4}-2.5^{\prime}$ & $\mathrm{E}_{\mathrm{C} 4^{-} 5^{\prime}}$ & $\mathrm{E}_{\mathrm{C} 8^{-}-2.5^{\prime}}$ & $\mathrm{E}_{\mathrm{C} 8^{-}} 5^{\prime}$ & $\mathrm{E}_{\mathrm{C} 12^{-2.5}}$ & $\mathrm{E}_{\mathrm{C} 12^{-}} 5^{\prime}$ \\
\hline$T_{\mathrm{g}}\left({ }^{\circ} \mathrm{C}\right)$ & 148.2 & 134.5 & 130.9 & 130.0 & 129.6 & 134.9 & 125.9 & 139.2 & 129.7 & 141.2 & 132.6 \\
\hline$\nu_{\mathrm{e}}\left(\mathrm{mol} \mathrm{m}^{-3}\right)$ & 2563 & 2293 & 2117 & 2185 & 2152 & 1886 & 1753 & 2383 & 2173 & 2082 & 2020 \\
\hline
\end{tabular}

absolute temperature at $T_{\mathrm{g}}+40{ }^{\circ} \mathrm{C}$. The values of crosslinking densities of $\mathrm{E}_{\mathrm{H}}$ systems and $E^{\prime}$ systems were listed in Table 6. The glass transition temperature $\left(T_{\mathrm{g}}\right)$ was defined as the peak temperature of a damping $(\tan \delta$ ) curve and the values were listed in Table 6 . The $T_{\mathrm{g}}$ of cured $\mathrm{E}_{\mathrm{H}}$ system decreased slightly with the increase of content of H-DDM. Besides, all of the cured epoxy systems had similar sharp single $\tan \delta$ peaks. It may signify that these systems were pure and homogeneous (Fig. 7b and 9$) \cdot{ }^{34}$

The DMA results of $E^{\prime}$ systems were showed in Fig. 8, 9 and Table 6. It was noted that the storage modulus of these systems in glassy region show little difference while the storage modulus in rubbery region decline slightly with increasing of content of single-ended amine. The $T_{\mathrm{g}}$ of cured $E^{\prime}$ system decreased sharply with the increasing of content of side chains. The loading of single-ended aliphatic amine reduced the dosage of curing agent so that the rigidity of the whole crosslinking

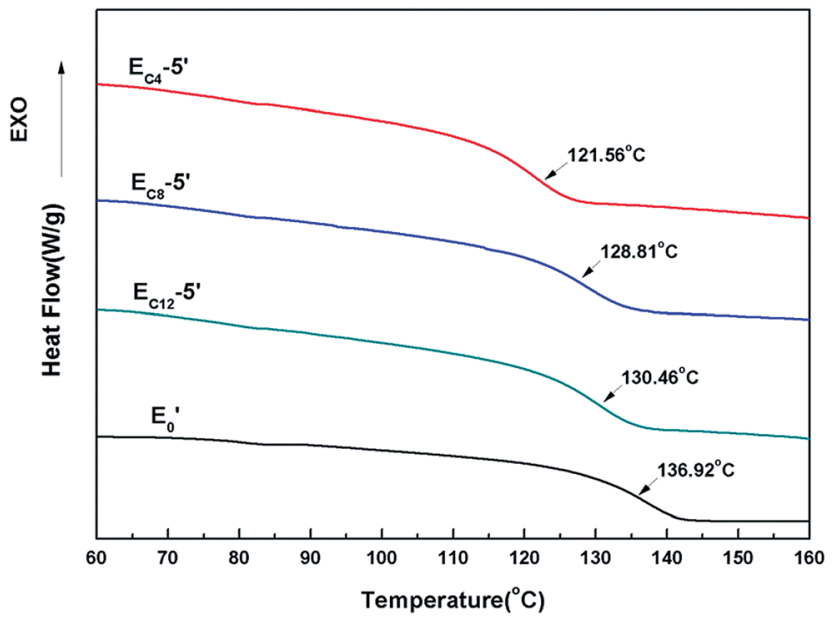

Fig. 10 DSC thermograms of $E_{0}^{\prime}, E_{C 4}-5^{\prime}, E_{C 8}-5^{\prime}$ and $E_{C 12}-5^{\prime}$ systems. networks was reduced, which led to the decrease of $T_{\mathrm{g} \cdot{ }^{35}}$ Furthermore, with the increasing of the length of the side chain, the effect of $T_{\mathrm{g}}$ was lower.

The thermal properties of $\mathrm{E}_{0}{ }^{\prime}, \mathrm{E}_{\mathrm{C} 4}-5^{\prime}, \mathrm{E}_{\mathrm{C} 8}-5^{\prime}$ and $\mathrm{E}_{\mathrm{C} 12}-5^{\prime}$ were further investigated by the DSC. The variation tendency of $T_{\mathrm{gDSC}}$ was similar with $T_{\text {gDMA }}$. Longer length of the side chain, less effect of $T_{\mathrm{g}}$. This was due to the increasing molecular weight of single-ended aliphatic amine. The molar value of the same mass decreased with increasing of the chain length. Besides, no exothermic peaks were found in the process of elimination of heat history. It was demonstrated that the curing reaction was completed (Fig. 10).

\section{Conclusion}

A series of epoxy systems with tunable rigid-flexibility containing side aliphatic dangling chains (DGEBF/DDM/H-DDM/ $n$-octylamine system) and a series of epoxy systems with different length of side chains (DGEBF/DDM/H-DDM/singleended aliphatic amine system) were designed and prepared. The nano- and submicron-sized phase separations were observed by AFM. It was speculated that the participation of side chains into the epoxy network, the compatibility between the side chain and the main chain and the rigidity of the backbone both influenced the microphase separation. Diffraction peaks were not observed in the wide angle X-ray scattering (WAXS) characterization which revealed that there was no crystallization in the modified epoxy resin. Besides, nanoIR characterization proved that the aggregation of aliphatic chains led to the microphase separation structure, which could remarkably improve the mechanical properties of cured epoxy resins. Especially, the $E_{\mathbf{C} 8}-5^{\prime}$ sample exhibited splendid mechanical properties with an attractive tensile strength of $88.4 \mathrm{MPa}$, an elongation at break of $6.6 \%$ and a tensile modulus of $3.5 \mathrm{GPa}$. 


\section{Conflicts of interest}

There are no conflicts to declare.

\section{Acknowledgements}

The authors gratefully acknowledge the financial support from the National Key Research Program of China under Grant No. 2016 YFB0302000.

\section{References}

1 E. M. Petrie, Epoxy Adhesive Formulations, McGraw Hill Professional, New York, 2005.

2 T. Vidil, F. Tournilhac, S. Musso, A. Robisson and L. Leibler, Prog. Polym. Sci., 2016, 62, 126-179.

3 N. T. Kamar and L. T. Drzal, Polymer, 2016, 92, 114-124.

$4 \mathrm{H}$. Zhou and S. Xu, Mater. Lett., 2014, 121, 238-240.

5 D. Quan and A. Ivankovic, Polymer, 2015, 66, 16-28.

6 W. Thitsartarn, X. Fan, Y. Sun, J. C. C. Yeo, D. Yuan and

C. He, Compos. Sci. Technol., 2015, 118, 63-71.

7 C. Declet-Perez, L. F. Francis and F. S. Bates, Macromolecules, 2015, 48, 3672-3684.

8 J. Liu, Z. J. Thompson, H.-J. Sue, F. S. Bates, M. A. Hillmyer, M. Dettloff, G. Jacob, N. Verghese and H. Pham, Macromolecules, 2010, 43, 7238-7243.

9 V. Rebizant, A. Venet, F. Tournilhac, E. Girardreydet, C. Navarro, A. Jeanpierre Pascault and L. Leibler, Macromolecules, 2004, 37, 8017-8027.

10 F. H. Gojny, M. H. G. Wichmann, U. Köpke, B. Fiedler and K. Schulte, Compos. Sci. Technol., 2004, 64, 2363-2371.

11 P. Guo, X. Chen, X. Gao, H. Song and H. Shen, Compos. Sci. Technol., 2007, 67, 3331-3337.

12 L. S. Schadler, S. C. Giannaris and P. M. Ajayan, Appl. Phys. Lett., 1998, 73, 3842-3844.

13 Y. Poonpipat, K. Leelachai, R. A. Pearson and P. Dittanet, J. Reinf. Plast. Compos., 2017, 36, 1156-1167.

14 P. L. Teh, M. Mariatti, H. M. Akil, C. K. Yeoh, K. N. Seetharamu, A. N. R. Wagiman and K. S. Beh, Mater. Lett., 2007, 61, 2156-2158.

15 P. Rosso, L. Ye, K. Friedrich and S. Sprenger, J. Appl. Polym. Sci., 2006, 100, 1849-1855.
16 C. B. Ng, L. S. Schadler and R. W. Siegel, Nanostruct. Mater., 1999, 12, 507-510.

17 P. Carballeira and F. Haupert, Polym. Compos., 2010, 31, 1241-1246.

18 L. M. McGrath, R. S. Parnas, S. H. King, J. L. Schroeder, D. A. Fischer and J. L. Lenhart, Polymer, 2008, 49, 999-1014.

19 S. Zhao, L. Schadler, R. Duncan, H. Hillborg and T. Auletta, Compos. Sci. Technol., 2008, 68, 2965-2975.

20 R. Konnola, J. Parameswaranpillai and K. Joseph, Polym. Compos., 2016, 37, 2109-2120.

21 Z. G. Shaker, R. M. Browne, H. A. Stretz, P. E. Cassidy and M. T. Blanda, J. Appl. Polym. Sci., 2010, 84, 2283-2286.

22 G. Hou, X. Chen, J. Liu and X. Sang, Polym.-Plast. Technol. Eng., 2011, 50, 1208-1213.

23 L. Luo, Y. Meng, T. Qiu and X. Li, J. Appl. Polym. Sci., 2013, 130, 1064-1073.

24 B. De and N. Karak, J. Mater. Chem. A, 2013, 1, 348-353.

25 T. Yang, R. Wang, X. Hou, J. Cheng and J. Zhang, Mater. Lett., 2016, 166, 150-153.

26 L. Ba, Q. Zou, X. Tan, J. Song, J. Cheng and J. Zhang, RSC Adv., 2016, 6, 91875-91881.

27 F. S. Ruggeri, G. Longo, S. Faggiano, E. Lipiec, A. Pastore and G. Dietler, Nat. Commun., 2015, 6, 7831.

28 A. M. Katzenmeyer, V. Aksyuk and A. Centrone, Anal. Chem., 2013, 85, 1972-1979.

29 S. Krimm and A. V. Tobolsky, J. Polym. Sci., 1951, 7, 57-76.

30 J. A. Pople, G. R. Mitchell, S. J. Sutton, A. S. Vaughan and C. K. Chai, Polymer, 1999, 40, 2769-2777.

31 S. Ghosh, N. A. Kouamé, L. Ramos, S. Remita, A. Dazzi, A. Denisetbesseau, P. Beaunier, F. Goubard, P. H. Aubert and H. Remita, Nat. Mater., 2015, 14, 505.

32 F. F. D. Nograro, R. Llano-Ponte and I. Mondragon, Polymer, 1996, 37, 1589-1600.

33 Y. Lu and R. C. Larock, Biomacromolecules, 2008, 9, 33323340.

34 K. Song, Y. Zhang, J. Meng and M. L. Minus, Polymer, 2015, 75, 187-198.

35 H. C. Erythropel, S. Shipley, A. Börmann, J. A. Nicell, M. Maric and R. L. Leask, Polymer, 2016, 89, 18-27. 